\title{
CURRÍCULO INTEGRADO NA EDUCAÇÃO PROFISSIONAL: Concepções de Alunos e Professores Sobre Projeto Integrador
}

\author{
Fabrício Gurkewicz Ferreira ${ }^{1}$ \\ Lediane Fani Felzke²
}

\begin{abstract}
RESUMO
Este artigo tem por objetivo verificar a percepção de um grupo de professores e de alunos a respeito dos limites e possibilidades da realização de um projeto integrador em uma instituição de Educação Profissional e Tecnológica na tentativa de efetivar o currículo integrado. Para a metodologia foi utilizada a pesquisa participante. Como resultados, constatamos que o projeto integrador colabora de maneira significativa no processo de ensino e aprendizagem, inclusive na temática proposta, qual seja, as corporalidades indígenas, pois buscou a integração entre as diversas áreas do conhecimento. Como pontos positivos apontamos a aproximação das disciplinas, a valorização da diversidade cultural, a realização de atividades interdisciplinares e a diminuição da quantidade de atividades avaliativas. Já como pontos negativos, temos o pouco tempo para a realização da proposta, a falta de espaços adequados para a sua preparação e a ausência de comprometimento de alguns professores e alunos. O desenvolvimento desta pesquisa mostrou-nos que o projeto integrador é uma ferramenta valiosa para a instituição do currículo integrado no ambiente escolar, sobretudo na Educação Profissional e Tecnológica. O seu êxito, contudo, está condicionado à maior articulação de esforços entre gestores públicos, gestores escolares, professores e alunos.
\end{abstract}

Palavras-chave: Educação profissional e tecnológica. Currículo Integrado. Projeto Integrador.

\section{INTEGRATED CURRICULUM IN PROFESSIONAL EDUCATION: CONCEPTIONS OF STUDENTS AND TEACHERS ON INTEGRATOR PROJECT}

\begin{abstract}
This paper aims to verify the perception of a group of teachers and students regarding the limits and possibilities of carrying out an integrator project in an institution of Professional and Technological Education, in an attempt to implement the integrated curriculum. Participative research was used for the methodology. As a result, we found that the integrator project collaborates significantly in the teaching and learning process, including the proposed theme, which is, indigenous corporealities, as it sought integration between the various areas of knowledge. As positive points we point out the approximation of the disciplines, the valorization of cultural diversity, the accomplishment of interdisciplinary activities and the reduction of the amount of evaluative activities. As negative points, we have little time to carry out the proposal, the lack of adequate spaces for its preparation and the lack of commitment of some teachers and students. The development of this research showed us that the integrator project is a valuable tool for the implementation of the integrated curriculum in the school environment, especially in Professional and Technological Education. However, its success is conditioned to a greater articulation of efforts between public managers, school managers, teachers and students.
\end{abstract}

Keywords: Professional and Technological Education. Integrated Curriculum. Integrator Project.

RECEBIDO EM: 26/3/2020

ACEITO EM: 30/6/2020

\footnotetext{
1 Autor correspondente. Instituto Federal de Rondônia - IFRO, Campus Ji-Paraná. Rua Rio Amazonas, 151 - Jardim dos Migrantes. CEP 78960000. Ji-Paraná/RO, Brasil. http://lattes.cnpq.br/2538321377732793. https://orcid.org/0000-0001-8834-0808. fabricio.gurkewicz@ifro.edu.br

2 Instituto Federal de Rondônia - IFRO, Campus Ji-Paraná. Ji-Paraná/RO, Brasil. http://lattes.cnpq.br/3064363709108828. https://orcid. org/0000-0002-5367-1209. lediane.fani@ifro.edu.br
} 
Este artigo apresenta resultados obtidos por meio de uma experiência com um Projeto Integrador (PI) em uma instituição de Educação Profissional e Tecnológica (EPT), na qual os seus participantes apontam os limites e as possibilidades desse método. As bases teóricas para o seu desenvolvimento estão calcadas em estudos relacionados ao currículo, currículo integrado e PI.

O currículo torna possível, no ambiente escolar, o acesso aos conhecimentos historicamente produzidos pela sociedade. Esses conhecimentos, no entanto, são apresentados de forma compartimentada em disciplinas, em razão de um processo histórico de fragmentação. Essa especialização das áreas dos saberes dificulta o processo formativo dos alunos, posto que vai de encontro à forma como estes veem a realidade social, que transcorre em uma perspectiva integralizadora e abrangente. Na tentativa de superar as limitações observadas com o conhecimento fragmentado no espaço escolar, surgem as propostas de integração curricular.

O currículo integrado tem por finalidade construir, de forma conjunta, as ações das disciplinas no ambiente escolar. O seu estabelecimento é uma oportunidade valiosa para que, de fato, se alcance uma educação integral, pois torna possível explorar todo o potencial da prática educativa em todas as suas dimensões, concorre na superação da visão utilitarista do ensino e fomenta o desenvolvimento das capacidades de pensar, sentir e agir dos estudantes. Atualmente, diferentes metodologias vêm sendo utilizadas para a concretização do currículo integrado e, dentre elas, temos o PI.

$\mathrm{O}$ PI visa à realização de propostas por duas ou mais disciplinas em torno de um tema comum. Henrique e Nascimento (2015) entendem o PI como um componente curricular que viabiliza a introdução de proposições integradoras em instituições de Ensino Médio e Superior. A sua presença no currículo oficial assegura o desenvolvimento de ações que concebem o conhecimento como fruto de uma totalidade social, além de ser situado historicamente.

Assim sendo, reconhecendo a importância de propostas curriculares que busquem a integração das disciplinas e a necessidade de desenvolvimento de propostas que intentem tal fim, como o PI, analisaremos as percepções de professores e alunos a respeito de um $\mathrm{PI}$ sobre as corporalidades indígenas ${ }^{3}$ desenvolvido com uma turma de 3 o ano do curso técnico de informática integrado ao Ensino Médio do Instituto Federal de Rondônia (Ifro), Campus Ji-Paraná, no ano de 2019. Para tanto, iniciaremos situando conceitualmente currículo, currículo integrado e PI. Em seguida, apresentaremos o percurso metodológico constituído pelo desenvolvimento de uma pesquisa participante, a qual se mostrou mais adequada em razão de possibilitar o trato com a problemática por meio de uma ação coletiva e colaborativa. Por fim, analisaremos as respostas dos professores e dos estudantes que participaram da pesquisa à luz da literatura científica, e traremos algumas considerações a respeito do trabalho desenvolvido.

Utilizamos esse termo para nos referirmos aos conhecimentos e às formas de intervir sobre o corpo praticadas pelas etnias ameríndias. 


\section{CURRÍCULO, CURRÍCULO INTEGRADO E PROJETO INTEGRADOR}

O currículo pode ser entendido como um projeto construído a partir de um plano ordenado que articula diferentes princípios visando à sua realização, e que nesse processo de concretização demonstra o seu valor. A sua materialização somente torna-se possível em razão do diálogo entre as partes, as quais estão diretamente relacionadas com ele, como os agentes sociais, os elementos técnicos, os professores, os alunos, dentre outros (SACRISTÁN, 2000).

Para Machado (2009), o currículo refere-se às ideias que subsidiam a organização do trabalho didático-pedagógico e que se revelam no desenvolvimento da prática educativa. Ele possibilita a materialização de experiências que necessitam de investigação e análise. A sua constituição tem como base a análise de ações já desenvolvidas, assim como o prognóstico do que se quer e até onde se pode conseguir chegar, a fim de se construir práticas pedagógicas exitosas. Desse modo, o currículo “...será sempre uma construção dinâmica, concretizada nas relações pedagógicas, cujo sucesso depende da participação e da capacidade de autoavaliação destas práticas pelos sujeitos que as tecem" (MACHADO, 2009, p. 52).

Segundo Fernandes (2014), não há um consenso em relação ao conceito de currículo. Isto ocorre em razão da indefinição do que deve estar presente nele e como deve ser organizado, uma vez que é influenciado por diferentes concepções de educação e bases teóricas. Sendo a escola, contudo, concebida como uma instituição que atua diretamente na formação de sujeitos autônomos e conscientes, que consigam participar de forma crítica e ativa em uma sociedade na qual as mudanças ocorrem constantemente, os conhecimentos e a forma como eles serão desenvolvidos tornam-se fundamentais, reforçando o papel precípuo do currículo.

Por ser fruto de uma construção social situada historicamente, no currículo estão presentes as experiências e os objetivos de aprendizagem que a escola considera necessários alcançar. A sua efetividade não se restringe apenas à transmissão dos conteúdos, mas também está condicionada aos componentes políticos, administrativos, estruturais, materiais e ao processo formativo dos professores.

Para Moreira e Candau (2008), apesar de as concepções sobre os currículos apresentarem bases teóricas específicas, podemos assinalar que as discussões sobre ele envolvem os conhecimentos escolares, os fatores procedimentais e oriundos das relações sociais que interferem em como se dará o processo de ensino e aprendizagem e as mudanças que queremos provocar nos alunos e nas alunas em âmbito de valores e de construção de identidades.

A dificuldade em se estabelecer as funções e as formas que o currículo apresenta relaciona-se com o fato de que os elementos de cada sistema educativo, em seus níveis e modalidades, além dos princípios de caráter filosófico, pedagógico e social que o regem, são diversos, contraditórios e se entrelaçam nos fenômenos educativos (SACRISTÁN, 2000). 
Nesse sentido, a sua finalidade estará diretamente relacionada com o grau educativo a que estiver vinculado. Embora isso constitua uma dificuldade na elaboração de uma definição mais abrangente sobre o currículo, também indica a cautela que se deve ter em não estabelecer teorizações universais a seu respeito a partir de proposições simples.

A transformação do currículo em um instrumento adequado às necessidades atuais dos alunos é uma tarefa árdua, uma vez que ele adquire sentidos concretos por meio das atividades práticas as quais possibilita. Estas, por sua vez, são compostas por diferentes contextos que “...são produtos de tradições, valores e crenças muito assentadas, que mostram sua presença e obstinação à mudança quando uma proposta metodológica alternativa pretende instalar-se em certas condições já dadas" (SACRISTÁN, 2000, p. 28).

A falta de autonomia é uma das grandes questões que recai sobre aqueles que se encontram envolvidos com as práticas curriculares, sobretudo alunos e professores. É difícil imaginar os professores conseguindo desenvolver metodologias inovadoras que permitam a emancipação dos alunos, quando o seu processo de criação passa por algum tipo de controle.

Um projeto curricular que favoreça a emancipação deverá apresentar alguns princípios, conforme Sacristán (2000): a) a reflexão será um eixo central, em que conduzirá as situações de planejamento, ação e avaliação; b) o processo de criação do currículo não pode se separar das condições concretas de sua realização; c) a construção curricular precisa considerar a interação entre o mundo social e cultural; d) o currículo, sendo fruto de uma construção social, deve estimular os alunos a refletir sobre o conhecimento que adquirem.

Ramos (2005) afirma que o currículo escolar tem a responsabilidade de selecionar os conhecimentos construídos socialmente e situados historicamente. Segundo a autora, a estrutura formal dos currículos demanda a organização dos conhecimentos, seja por projetos e disciplinas, dentre outros. Desse modo, embora haja diferentes formas de organização do currículo, é fundamental que os conceitos se mantenham vinculados ao referencial científico presente em cada disciplina, sobretudo para que seja possível o desenvolvimento de uma proposta interdisciplinar.

Uma das marcas históricas do currículo, especialmente no Ensino Médio, é a sua fragmentação (ARAÚJO; FRIGOTTO, 2015; CRUZ et al., 2015; RAMOS, 2005; SAVIANI, 2007). Isso significa que as áreas do conhecimento não interagem entre si, permanecendo estanques, e os saberes são desenvolvidos por meio de parcelas de modo linear. Como consequência, formam-se alunos que conseguem responder bem aos instrumentos avaliativos escolares, mas que não são capazes de entender a realidade que os rodeia de forma estruturada.

A prevalência histórica da fragmentação curricular justifica-se pelo fato de que, nas culturas escolares, em que a separação dos conteúdos já é parte integrante de suas diretrizes, a resistência à introdução de mudanças é muito maior. A organização curricular está diretamente relacionada com o modo que os professores são escolhidos e como desenvolvem o seu trabalho profissional. A vigência, então, de uma determinada 
estrutura curricular por um período prolongado, acarreta no surgimento de um sentimento de identidade profissional atrelado a essa estrutura e à organização da escola (SACRISTÁN, 2000).

Com a necessidade de se tentar compreender a dinâmica social, que se apresenta cada vez mais complexa, iniciativas que visam à realização de diálogos entre os saberes tornam-se fundamentais. Atualmente, o currículo integrado é uma proposição consolidada na área curricular, sobretudo no âmbito da Educação Profissional e Tecnológica (EPT), como uma alternativa para a superação da fragmentação.

A proposta de integração curricular acompanhou o currículo durante o seu percurso histórico com distintas denominações: currículo global, metodologia de projetos, currículo interdisciplinar, dentre outros. A questão da integração é tão relevante que, mesmo as propostas curriculares centradas nas disciplinas, acreditam que estabelecer formas de integrar as disciplinas devem ser discutidas. A integração, portanto, não é exclusividade das propostas curriculares críticas e nem das teorias mais recentes (LOPES; MACEDO, 2011).

Machado (2009) refere-se ao currículo integrado como uma proposta que tenha por finalidade a articulação entre conteúdos que apresentam estruturas diferentes, que, embora devam ser reconhecidas, não devem ser observadas com rigor absoluto. No âmbito da EPT, esses conteúdos a serem relacionados são denominados de gerais e profissionais. Para que haja a possibilidade de sucesso com a integração curricular, é fundamental que a aproximação entre as áreas do conhecimento se acentue de forma progressiva, visando o desenvolvimento de ações didáticas organizadas, em que a atuação de cada disciplina sintetize uma parte estruturada do todo.

A concretização da integração curricular demanda uma mudança de postura tanto dos professores quanto dos alunos. É necessário o rompimento com o modelo hierárquico do conhecimento, em que algumas disciplinas são menosprezadas, como as de cunho técnico, por exemplo, por serem associadas, de forma discriminatória, ao trabaIho manual. É indispensável, todavia, a predisposição dos sujeitos envolvidos no processo de ensino e aprendizagem para a superação da fragmentação dos conhecimentos, mobilizando esforços para o desenvolvimento de inter-relações entre as áreas, de modo que se construa, nas práticas educativas, um entendimento global e complexo do conhecimento (MACHADO, 2009).

O currículo integrado em uma instituição de EPT deverá viabilizar a integração entre a formação geral, técnica e política. Os conteúdos relacionados aos conhecimentos gerais referem-se aos conceitos que atuam como "leis gerais" na explicação dos fenômenos. Os conteúdos técnicos dizem respeito à aplicação de conceitos de forma contextualizada com finalidades específicas. Quando se fala na separação entre os conhecimentos específicos e gerais está-se referindo apenas à questão metodológica, posto que, epistemologicamente, eles formam uma unidade (ARAÚJO; FRIGOTTO, 2015; RAMOS, 2005). 
Segundo Sacristán (2000), o currículo, sob uma perspectiva integradora em detrimento da fragmentária, torna mais viável o estabelecimento de relações, considerando que estimula e valoriza a diversidade. Além disso, a lógica que rege o conhecimento especializado isenta-o de se associar com o conhecimento particular, proveniente do contexto social dos alunos, devendo, apenas, responder à sua ordenação interna.

Nessa direção, Fernandes (2014) assinala diferenças entre o currículo disciplinar e o integrado no processo formativo dos estudantes. Para o autor, o currículo disciplinar, por ser desconectado da realidade e não considerar a contribuição de alunos e professores na seleção de conteúdos, limita o processo formativo. Já o currículo integrado, ao fomentar a participação dos alunos no processo de aprendizagem, potencializa a sua formação crítica.

A concepção de uma proposta curricular integrada constitui-se, obrigatoriamente, em um ato coletivo, no qual está presente a organização do planejamento e a definição de metodologias e objetivos. A sua construção somente torna-se possível em um espaço democrático e participativo. Caso não seja assim, é improvável que se materialize nas práticas educativas (ARAÚJO; FRIGOTTO, 2015).

Silva (2014) afirma que o planejamento coletivo é uma ferramenta fundamental na construção de uma proposta integrada, posto que possibilita a socialização de ideias e visões de educação. Também é o momento no qual são definidas as estratégias e realizada a avaliação. É nesse processo que se torna possível a compreensão da dinâmica escolar e a concretização do currículo integrado. O autor salienta, ainda, que o planejamento constante é um elemento imprescindível na efetivação do currículo integrado, uma vez que é "por meio do planejamento coletivo, consciente, crítico e intencional que as equipes constroem relações de totalidade e vão se fortalecendo para avançar na efetivação do currículo integrado" (SILVA, 2014, p. 24).

Ramos (2005) defende uma proposta de integração em que os conteúdos não se limitam a funcionar como base para o desenvolvimento de competências ou para se encerrar em si mesmo, mas representam a apropriação histórica da realidade social e material realizada pelo homem e expressada em conceitos e teorias. Para a autora, a organização dessa proposta é sustentada por dois princípios filosóficos, quais sejam: o homem como produtor de sua existência por meio da intervenção sobre a realidade e esta como fruto de múltiplas relações.

Os desafios para a instalação do currículo integrado, principalmente na EPT, estão atrelados ao seu vínculo histórico com uma formação tecnicista. No currículo sob essa perspectiva, que é regido pelos pressupostos do empirismo e do mecanicismo, a sua organização ocorre de forma fragmentária, na qual as disciplinas são portadoras de conteúdos de ensino, isoladas entre si e desconectadas da realidade. Desse modo, a realização da interdisciplinaridade nessa concepção é inviável, posto que os arranjos metodológicos esbarrariam em associações mecânicas entre fatos e conceitos (RAMOS, 2005).

Para Crizel, Passos e Del Pino (2013), a integração curricular constitui-se em um grande desafio aos sistemas de educação no país, uma vez que demanda a ressignificação do processo formativo, o qual deverá viabilizar a construção de sujeitos autônomos e intelectualmente capazes a partir da interação com a realidade em que estão inseridos e da intervenção sobre ela. 
Cruz et al. (2015) ressaltam que, dentre as dificuldades enfrentadas para a efetivação do currículo integrado, observa-se a escassez de propostas que possam ser seguidas, posto que a ideia da integração ainda é nova e necessita do engajamento dos profissionais e gestores das instituições educacionais.

Nessa perspectiva de que modelos a serem seguidos ainda são incipientes, Silva (2014) assevera que a busca por soluções aos desafios apresentados pelo currículo integrado caberá aos sujeitos envolvidos no processo a partir das escolhas feitas. Dessa forma, torna-se extremamente importante que todos tenham a compreensão dos objetivos a serem alcançados e do papel exercido por eles. Isso só possível com ações sistemáticas de estudo e planejamento, em que os envolvidos respeitem as diferenças e estejam abertos às inovações no ambiente escolar.

Apesar de haver especificidades a serem consideradas em cada contexto, tais como materiais, de estrutura e pessoal, Ramos (2005) aponta quatro elementos que devem guiar a concepção de um currículo integrado. O primeiro deles é a problematização dos fenômenos e fatos relevantes para a compreensão do mundo em que vivemos. Para a autora, isto significa realizar questionamentos a respeito dos fenômenos, fatos, situações, dentre outros, a fim de compreendê-los em sua essência, o que nem sempre é fácil de acontecer.

O segundo é a explicitação de teorias e conceitos fundamentais. A sua finalidade é permitir o entendimento mais amplo da natureza do objeto estudado a partir de diferentes perspectivas, em que se procura observá-lo no seu próprio campo científico e na relação com os outros campos. O terceiro diz respeito à identificação dos conceitos, tanto de formação geral quanto específica, valendo-se de sua base científica, bem como da sua relação com aspectos tecnológicos, sociais e culturais. Nesse tópico, a ênfase está na importância da dimensão geral e específica do conhecimento, assim como nas suas possibilidades de interação, embora cada conceito, da formação geral ou específica, possua características próprias (RAMOS, 2005).

Por fim, o quarto refere-se à organização dos componentes curriculares e das práticas pedagógicas, tendo como referência a localização dos conceitos e as suas múltiplas relações. Desse modo, o entendimento da realidade concreta como produto da interação de diversas determinações torna-se possível (RAMOS, 2005).

Como podemos observar, a efetivação do currículo integrado no ambiente escolar, sobretudo na EPT, é primordial, mas, ao mesmo tempo, também é desafiador, uma vez que as práticas curriculares fragmentadas ainda estão enraizadas na cultura escolar e a sua superação não é uma tarefa simples. Nesse sentido, há algumas alternativas para potencializar a inserção do currículo integrado e, dentre elas, temos o Projeto Integrador (PI).

O PI tem em sua estrutura teórico-metodológica a presença de diferentes concepções, orientadas por ideias oriundas de diversos autores e que, muitas vezes, são utilizadas de forma conjugada (SILVA, 2014). No caso desta pesquisa, compreendemo-lo como uma proposta que aproxima diferentes áreas do conhecimento, tendo como referência um tema comum. Deste modo, sua concepção, planejamento, execução e avalição ocorrem por meio do trabalho coletivo entre as disciplinas participantes. 
Assim como as questões gerais encontradas no ambiente escolar, o PI é permeado por discussões, contradições e percalços. A sua finalidade pode estar direcionada tanto para a edificação de uma sociedade mais justa por meio da superação dos princípios capitalistas quanto para a subserviência ao mercado e a sua lógica competitiva (SILVA, 2014).

Nesse sentido, o PI deve atuar na superação da dicotomia entre a teoria e a prática, bem como da fragmentação do conhecimento, que, no espaço escolar, se observa por meio das disciplinas. Para tanto, é fundamental a realização de discussões e reflexões que procurem uma melhor compreensão dos PIs, sobretudo porque ainda é quase inexistente a socialização de experiências nesse campo que indiquem caminhos para que ocorra a integração entre conceitos, disciplinas e áreas de conhecimento (HENRIQUE; NASCIMENTO, 2015).

Silva (2014) destaca seis contribuições do PI para a efetivação do currículo integrado: 1) direciona para a realização do trabalho coletivo entre os docentes e para a articulação entre as áreas do conhecimento; 2) incentiva os estudantes a se dedicarem tanto a temas da formação básica quanto da formação técnica; 3) mobiliza esforços para a solução de problemas científicos e sociais, 4) promove o envolvimento com a pesquisa e enfatiza a importância de relacionar diferentes saberes e informações; 5) associa a teoria e a prática; e, finalmente; 6) fomenta o progresso individual e coletivo.

As vivências e os desdobramentos do PI indicam a necessidade de se valorizar o papel dos sujeitos participantes da proposta, bem como da bagagem de conhecimentos que estes possuem. Desse modo, possibilita-se aos estudantes um maior protagonismo no seu processo de aprendizagem e a construção de um conhecimento com maior significância, posto que tem como ponto de partida as suas próprias experiências.

O foco de um PI, portanto, deve estar voltado para a formação humana, tendo em vista privilegiar o desenvolvimento de aprendizagens em detrimento da absorção de conteúdos. A sua concretização está relacionada com a efetivação de ações de caráter democrático, além de preocupadas com a coletividade, “... uma vez que a maioria dos projetos desenvolvidos busca solucionar problemas vividos cotidianamente pelos alunos, apontando assim, para o caminho da formação integral dos sujeitos: crítica, cidadã, participativa e coletiva" (SILVA, 2014, p. 66).

O êxito de um PI está condicionado a vários aspectos, tais como um novo arranjo curricular e dos conteúdos, tempo para o planejamento coletivo, predisposição para o trabalho coletivo, condições materiais e estruturais. Na verdade, esses fatores são os principais entraves para o seu desenvolvimento (SILVA, 2014).

A introdução de um PI depende de tempos e espaços adequados para realizar a sistematização. A desconsideração desses aspectos pode fazer com que o seu desenvolvimento colabore para a permanência da lógica disciplinar e fragmentária. Há casos em que ele tem por finalidade a integração, mas é incluído como uma atividade extracurricular, na qual apenas um professor é responsável e a ação não é de caráter institucional. Há outros em que se torna um componente curricular e tem por objetivo a geração de um produto, mas continua sendo de responsabilidade de apenas um professor. Nesse sentido, a proposta até mobiliza os esforços e os interesses dos estudantes, mas conti- 
nua sem viabilizar o trabalho interdisciplinar. Há, ainda, outros casos em ele é utilizado para a iniciação e desenvolvimento de pesquisa, mas também permanece com a estrutura disciplinar do conhecimento (SILVA, 2014).

A concretização do PI torna-se cada vez mais complexa, à medida que consideramos as situações a que os professores estão sujeitos no espaço escolar. Infraestrutura precária, salas de aula lotadas, nenhum incentivo à formação continuada, tempo limitado para o planejamento do trabalho e baixa remuneração, são alguns exemplos. O desenvolvimento de novas ações nesse ambiente, então, não diz respeito apenas à vontade individual, mas, sobretudo, à articulação dos esforços entre a escola, o governo e a sociedade. Essas condições estruturais irão limitar ou potencializar o surgimento de novas propostas.

Henrique e Nascimento (2015) listam três motivos que nos ajudam a entender as dificuldades em se desenvolver propostas integradoras no ambiente escolar. O primeiro está relacionado com a falta de formações específicas aos docentes voltadas para esse fim. O segundo diz respeito à falta de uma organização, por parte das instituições de ensino, no que se refere ao currículo e aos tempos e espaços adequados para que professores e alunos vivenciem tais experiência. $O$ terceiro tem relação à falta de predisposição dos docentes, por considerarem muito complexa a realização de um trabalho dessa natureza.

O problema das situações apresentadas não diz respeito aos pressupostos metodológicos para se efetivar a ação, mas sobre a maneira como ela está contribuindo para que se concretize o currículo integrado. O PI deve ser entendido como um instrumento que possibilite alcançar os objetivos pretendidos pelo curso, os quais só se tornam possíveis por meio de um trabalho coletivo e diário. Independentemente de ser responsabilidade de uma pessoa ou de um grupo, “... precisa ser constantemente atualizado e debatido por todos, impactando no trabalho de todos, servindo como ponto de partida para o trabalho interdisciplinar, como espaço para a realização de sínteses de processos, de criação, de experimentação e de problematização da realidade vivida por educandos e educadores" (SILVA, 2014, p. 67).

O desenvolvimento de um $\mathrm{PI}$ oferece-nos o ensejo de realizar ações que integrem disciplinas e/ou cursos, visando à consolidação de um currículo integrado voltado para a formação humana integral. Desse modo, ele só se torna efetivo caso esteja assentado em uma estrutura curricular que tenha por finalidade a formação humana integral e que seus conteúdos tenham como origem os saberes oriundos da natureza, do trabaIho, da tecnologia, da ciência e da cultura.

De acordo com Henrique e Nascimento (2015), há duas atitudes necessárias para a concretização de um PI. A primeira está relacionada aos professores, em que eles deverão aceitar e se comprometer com a proposta. $O$ estabelecimento do diálogo entre diferentes campos do saber demanda entendimento e respeito para com a diferença e a diversidade, bem como uma predisposição para se relacionar. A segunda refere-se às condições concretas de tempo e espaço nas instituições de ensino para que se conceba a proposição. 
A partir das ideias apresentadas, podemos constatar a viabilidade do currículo integrado como uma alternativa curricular que possibilita um processo formativo que aproxime e integre o estudante à sua realidade e o subsidie a agir sobre ela. Nesse sentido, o PI apresenta-se como uma ferramenta colaborativa à integração curricular, uma vez que aproxima as áreas do conhecimento em torno de um tema em comum, potencializando as suas ações. No caso do tema desta pesquisa - "as corporalidades indígenas" - a sua contribuição é significativa.

\section{PERCURSO METODOLÓGICO}

Para o delineamento do percurso desta investigação utilizamos como base a pesquisa participante. É um tipo de pesquisa que se caracteriza pela ação colaborativa entre os participantes que vivenciam determinada problemática visando à construção solidária do conhecimento. As suas ações buscam, portanto, envolver os beneficiários na produção do conhecimento.

Brandão (2006) aponta quatro finalidades da pesquisa participante: 1) a sua atuação vai ao encontro das demandas da problemática que lhe deu origem, que deverão ser trabalhadas de forma colaborativa; 2) possui uma vocação política e educativa em razão do seu caráter de aprendizado dialógico e coletivo; 3) a sua atuação contínua colabora para o surgimento de um saber popular que, em um processo de construção progressiva, poderia se tornar uma ciência popular; e 4) possibilita o empoderamento dos seus participantes.

Um dos pontos fundamentais dessa abordagem é o diálogo constante em detrimento de uma postura impositiva. A sua realização ocorre por meio de uma construção solidária, em que as diretrizes, os saberes e os valores são definidos de forma coletiva e não a partir de um desejo individual (BRANDÃO; BORGES, 2007). Desse modo, o termo "participante" neste tipo de pesquisa não ocorre em razão da presença de diversos sujeitos para a sua realização, mas, sim, por se constituir em uma ação social coletiva e colaborativa de construção do conhecimento, na qual se busca a transformação social a partir da emancipação dos seus integrantes (BRANDÃO, 2006).

De acordo com Brandão (2006, p. 27), "A pesquisa participante não cria, mas responde a desafios e incorpora-se em programas que colocam em prática novas alternativas de métodos ativos em educação...", ou seja, por meio desse tipo de investigação os seus participantes atuam diretamente na construção de conhecimentos relacionados à alguma problemática. No caso em tela, as corporalidades indígenas e o PI.

Assim, como esta pesquisa teve por objetivo verificar a viabilidade de um PI como um instrumento de construção do conhecimento de forma colaborativa e que torna o processo de ensino e aprendizagem mais significativo, acreditamos que essa vertente metodológica seja a mais adequada.

A amostra da pesquisa foi composta por 35 alunos da turma de 30 ano do curso de Informática do Ifro, Campus Ji-Paraná, do ano de 2019, que estudavam no período matutino, e por 8 professores, sendo 2 da disciplina de história e 1 das disciplinas de educação física, filosofia, língua portuguesa, língua espanhola, química (núcleo comum) e redes (núcleo técnico). 
Iniciamos as ações com a sensibilização dos alunos e de seus pais para a participação dos primeiros na pesquisa. Após uma reunião, em que explicamos os procedimentos a serem realizados, todos os alunos e seus pais concordaram com a participação, e os alunos assinaram o Termo de Assentimento Livre e Esclarecido (Tale), enquanto os seus pais assinaram o Termo de Consentimento Livre e Esclarecido (TCLE).

Concomitantemente, estabelecemos contato com os professores que ministram aulas na turma de 3 ano do curso de Informática do IFRO, Campus Ji-Paraná, no ano de 2019, que estudavam no período matutino, para verificar a disponibilidade e o interesse em participar do grupo colaborativo que construiria o projeto integrador. Na sequência, entregamos o Termo de Consentimento Livre e Esclarecido (TCLE) para aqueles que fossem participar.

A vigência do projeto foi de abril a outubro de 2019. Nesse período ocorreram oito encontros do grupo colaborativo dos professores, em que foram trabalhados conceitos referentes a currículo integrado, $\mathrm{PI}$, culturas indígenas e corporalidades indígenas. Também estabelecemos as ações que cada disciplina participante iria desenvolver, bem como o formato das avaliações.

O trabalho desenvolvido nas disciplinas participantes envolveu aulas expositivas, práticas e de campo, nas quais os alunos tiveram a oportunidade de conhecer mais sobre as culturas ameríndias, as suas corporalidades e, inclusive, ter um contato direto com os indígenas. Este contato aconteceu por meio da visita ao Centro Cultural e ao Centro de Plantas Medicinais dos Suruí Paiter em Cacoal - RO. Como atividades avaliativas do projeto, foi realizado um seminário e a construção de um artigo pelos alunos, ambos em grupo.

Para verificar os resultados do PI, aplicamos um questionário aos alunos em que buscamos conhecer as suas percepções a respeito da vivência de uma experiência integradora, e outro aos professores, em que eles expressaram as suas impressões sobre o $\mathrm{PI}$ e a contribuição dele para o aprendizado das corporalidades indígenas.

$\mathrm{Na}$ análise dos dados, apresentados a seguir, as respostas estão agrupadas de acordo com a sua proximidade em relação ao conteúdo. Dessa forma, nesta apresentação a sua organização se dá por meio de Quadros que contêm o tema da pergunta, o conjunto de respostas por aproximação, o Valor absoluto (V.a.) e a porcentagem (\%) de cada um dos conjuntos.

Juntamente com a apresentação dos resultados, procedemos a sua análise, tendo como referência trabalhos encontrados na literatura. A fim de facilitar o entendimento, nos dois primeiros tópicos - Limites e possibilidades do projeto integrador e As corporalidades indígenas como tema de um projeto integrador - fizemos a análise das respostas dos professores. No terceiro tópico - Percepções a respeito de um projeto integrador sobre as corporalidades indígenas - realizamos a análise das respostas dos alunos sobre o projeto integrador.

\section{RESULTADOS E DISCUSSÃO}

Ao longo deste artigo pudemos perceber que a concretização do currículo integrado, sobretudo na EPT, é uma condição fundamental para que ocorram avanços qualitativos nos processos de ensino e aprendizagem. O PI é uma das alternativas metodológicas utilizadas para a efetivação do currículo integrado e, embora as suas experiências ainda sejam recentes, vem apresentando bons resultados. 
Assim sendo, apresentaremos as percepções de professores e alunos a respeito da vivência de um PI. Como mencionado anteriormente, a fim de facilitar a compreensão, os resultados serão apresentados em três tópicos, os dois primeiros referentes às respostas dos professores e o terceiro às dos alunos.

\section{Limites e possibilidades do projeto integrador}

Nesse primeiro tópico a análise diz respeito aos limites e às possibilidades no desenvolvimento de um PI na EPT. Para tanto, as questões tiveram por objetivo verificar se as contribuições do PI para o aprendizado são maiores do que as disciplinas de forma isolada (Quadro 1), os pontos positivos e negativos do PI (Quadro 2) e sugestões para o seu aprimoramento (Quadro 3).

Quadro 1 - A contribuição do projeto integrador para o aprendizado é maior do que a atuação isolada das disciplinas

\begin{tabular}{|c|c|c|c|}
\hline \multicolumn{2}{|r|}{ Conjunto de respostas } & V.a. & $\%$ \\
\hline \multirow{4}{*}{ Sim } & Por promover a interação entre as diferentes áreas do conhecimento & 5 & 62,5 \\
\hline & $\begin{array}{l}\text { Porque permite o entendimento do conhecimento em uma } \\
\text { perspectiva plural }\end{array}$ & 1 & 12,5 \\
\hline & Pois mantém o conhecimento vinculado à realidade concreta & 1 & 12,5 \\
\hline & $\begin{array}{l}\text { Em razão de possibilitar uma maior participação dos alunos na } \\
\text { construção do conhecimento }\end{array}$ & 1 & 12,5 \\
\hline
\end{tabular}

Fonte: Questionário aplicado pelos autores.

Todos os professores acreditam que a atuação integrada das disciplinas, e as suas respostas, vão ao encontro de aspectos mencionados na literatura a respeito dos motivos que tornam as propostas integradoras mais significativas para a aprendizagem do que as propostas fragmentárias (HENRIQUE; NASCIMENTO, 2015; RAMOS, 2005; SILVA, 2014). É importante destacar, também, que os pontos mencionados se relacionam, e o seu êxito está condicionado a essa aproximação, posto que uma construção efetiva do conhecimento ocorre, de fato, quando ele é tratado de forma contextualizada, em que se estabelece o vínculo com a realidade dos alunos, e interdisciplinar, quando há interação entre as diferentes áreas do conhecimento.

Quadro 2 - Pontos positivos e negativos do projeto integrador

\begin{tabular}{|l|l|}
\hline \multicolumn{1}{|c|}{ Conjunto de respostas } \\
\hline \multirow{4}{*}{ Positivos } & Interação entre as disciplinas \\
\cline { 2 - 3 } & A participação de indígenas \\
\cline { 2 - 3 } & A participação ativa dos alunos na construção do conhecimento \\
\cline { 2 - 3 } & A realização de aulas de campo na aldeia \\
\cline { 2 - 3 } & A realização de pesquisa por parte dos alunos \\
\cline { 2 - 3 } & A construção do conhecimento de forma integrada \\
\hline \multirow{5}{*}{} & A resistência em relação ao tema por parte de alguns alunos \\
\cline { 2 - 3 } & Dificuldades em encontrar subsídios teóricos para trabalhar o tema \\
\cline { 2 - 3 } & Pouco tempo para o preparo e a execução das atividades \\
\cline { 2 - 3 } & Dificuldade para reunir os docentes participantes do projeto \\
\cline { 2 - 3 } & A má utilização de algumas atividades avaliativas \\
\cline { 2 - 3 } & A forma como o projeto foi finalizado \\
\cline { 2 - 3 } & Dificuldade em integrar a disciplina técnica no planejamento das ações \\
\cline { 2 - 3 } & A falta de comprometimento de alguns docentes \\
\hline
\end{tabular}

Fonte: Questionário aplicado pelos autores. 
Em relação aos pontos positivos, os professores apontaram diversos aspectos, os quais podem ser encontrados em outras experiências que também buscaram materializar o currículo integrado na EPT, seja por meio de um PI, por uma oficina de integração ${ }^{4}$ ou por projetos interdisciplinares, como a interação entre as disciplinas (CARVALHO, 2019), a participação ativa do aluno na construção do conhecimento (CARVALHO, 2019; CRUZ et al., 2015), a realização de pesquisa por parte dos alunos (CARVALHO, 2019; ROCHA; SILVA; FONSECA, 2017; GRÜMM; CONTE; LIDANI, 2016) e a construção do conhecimento de forma integrada (PAULON; VIEIRA, 2017; SILVA; GIOTTO, 2016; CRUZ et al., 2015).

No que se refere aos pontos negativos, também é possível encontrar situações semelhantes às apresentadas pelos professores em outros trabalhos, como a resistência por parte dos alunos (CARVALHO, 2019; LIMA, 2017), tempo insuficiente para o desenvolvimento da proposta (CARVALHO, 2019), a má utilização de atividades avaliativas (CARVALHO, 2019) e a falta de comprometimento de alguns docentes (CARVALHO, 2019; LIMA, 2017; OBERDERFER et al., 2016).

Os aspectos mencionados nas respostas, tanto positivos quanto negativos, indicam que o êxito de uma proposta integradora, como o PI, depende de diferentes fatores. O entendimento da proposta, contudo, por parte de gestores, professores e alunos, aliado ao seu comprometimento, ainda são o eixo fundamental.

\section{Quadro 3 - Sugestões para o aprimoramento do projeto integrador}

\section{Conjunto de respostas}

Apoio da gestão com a criação de tempos e espaços específicos para o planejamento e execução da proposta

Abranger mais temas e disciplinas

Incluir mais disciplinas técnicas

A forma como o projeto será finalizado

Ser ofertado em todo o Ensino Médio

Uma maior divulgação dos trabalhos desenvolvidos no projeto

Um período maior de tempo para a elaboração da proposta

Fonte: Questionário aplicado pelos autores.

As sugestões apresentadas pelos professores, especificamente as relacionadas ao apoio da gestão, a ampliação dos temas e disciplinas e do tempo para a elaboração da proposta, vão ao encontro dos resultados encontrados por Carvalho (2019), que buscou verificar o entendimento docente a respeito de interdisciplinaridade e projetos integradores no IFRN - Campus Pau dos Ferros. O apoio da gestão também foi apontado como sugestão pelos professores participantes da pesquisa realizada por Lima (2017), que buscou verificar a percepção de um grupo de professores a respeito das possibilidades de integração em um curso de Ensino Médio Integrado.

Segundo Silva (2014, p. 72), as oficinas de integração caracterizam-se pela "...criação de um ambiente que favoreça o diálogo e o aprendizado entre educadores e educandos, a experimentação, a reflexão e a teorização, a resolução de problemas do cotidiano e a participação efetiva de todos os envolvidos." 
Outro ponto destacado - a maior divulgação dos trabalhos desenvolvidos no projeto - foi contemplado em trabalhos desenvolvidos por Silva-Pereira, Santos e Oliveira Neto (2017) e Paulon e Vieira (2017), que, após desenvolverem experiências integradoras entre disciplinas do ensino técnico e do ensino básico, estenderam os resultados alcançados à comunidade externa às instituições, por meio de um jogo digital e banners, respectivamente.

\section{As corporalidades indígenas como tema de um projeto integrador}

Nesse segundo tópico a análise refere-se às perspectivas de um $\mathrm{PI}$, tendo como tema as corporalidades indígenas. Para tanto, as questões tiveram por objetivo verificar se os professores conheciam o tema (Quadro 4), se o consideravam relevante para a EPT (Quadro 5), se o trabalho apenas na sua disciplina seria melhor (Quadro 6) e de que forma o PI colaborou para que o aprendizado das corporalidades indígenas fosse significativo (Quadro 7).

Quadro 4 - Conhecimento a respeito do tema do projeto

\begin{tabular}{|l|c|c|}
\hline \multicolumn{1}{c|}{ Conjunto de respostas } & V.a. & $\%$ \\
\hline Não & 5 & 62,5 \\
\hline Sim & 3 & 37,5 \\
\hline
\end{tabular}

Fonte: Questionário aplicado pelos autores.

Quadro 5 - Relevância do tema para a Educação Profissional e Tecnológica

\begin{tabular}{|c|l|c|c|}
\hline \multicolumn{1}{|c|}{ Conjunto de respostas } & V.a. & $\%$ \\
\hline \multirow{4}{*}{$\operatorname{sim}$} & Pois valoriza a diversidade cultural existente no Brasil & $\mathbf{5}$ & $\mathbf{6 2 , 5}$ \\
\cline { 2 - 4 } & Mas desde que seja desenvolvido de uma forma interdisciplinar & $\mathbf{2}$ & $\mathbf{2 5}$ \\
\cline { 2 - 4 } & $\begin{array}{l}\text { Em razão de valorizar o contexto sociocultural em que o aluno está } \\
\text { inserido }\end{array}$ & $\mathbf{1}$ & $\mathbf{1 2 , 5}$ \\
\hline
\end{tabular}

Fonte: Questionário aplicado pelos autores.

As análises das respostas dessas duas questões nos mostram que, apesar de a maior parte dos professores não possuir um conhecimento anterior a respeito do tema, todos acreditam ser importante a sua inserção na EPT. Dentre as justificativas para tal entendimento, a valorização da diversidade cultural existente no Brasil também foi apontada em outros dois trabalhos - uma oficina de integração e um projeto interdisciplinar - realizados com a temática indígena na EPT.

Agne, Dalbosco e Jonck (2016) desenvolveram uma oficina de integração com uma turma do Proeja ${ }^{5}$, enquanto Cury, Souza e Moniz (2018) realizaram um projeto interdisciplinar com alunos do Ensino Médio integrado. Em ambas as experiências, o retorno positivo, assinalado pelas falas dos alunos e dos professores envolvidos na proposta, demonstra que a temática indígena pode colaborar de forma significativa no processo formativo dentro da EPT.

A utilização de uma experiência com um público diferente daquele utilizado neste texto, no caso a Educação de Jovens e Adultos, deve-se à escassez de trabalhos com a temática indígena e com o currículo integrado em instituições que atuam na EPT. 
Essa convergência de ideias no que se refere à valorização da diversidade cultural, mostra-nos que as propostas caminham na direção da contemplação de um dos princípios fundamentais da EPT, que é a formação humana integral (RAMOS, 2008). Este princípio é composto por três dimensões: trabalho, ciência e cultura. Dessa maneira, como as propostas incidem sobre uma das partes - a cultura - a sua pertinência na EPT é válida.

Quadro 6-O resultado do trabalho com esse tema seria melhor caso fosse feito por disciplina, de forma isolada

\begin{tabular}{|l|l|c|c|}
\hline \multicolumn{2}{|c|}{ Conjunto de respostas } & V.a. & $\%$ \\
\hline \multirow{2}{*}{ Não } & Pois a contribuição de cada disciplina foi fundamental & $\mathbf{7}$ & $\mathbf{8 7 , 5}$ \\
\cline { 2 - 4 } & Em razão das limitações da disciplina técnica & $\mathbf{1}$ & $\mathbf{1 2 , 5}$ \\
\hline
\end{tabular}

Fonte: Questionário aplicado pelos autores.

Quadro 7 -Contribuições do projeto integrador para que o aprendizado das corporalidades indígenas fosse significativo

\begin{tabular}{|l|}
\hline \multicolumn{1}{|c|}{ Conjunto de respostas } \\
\hline $\begin{array}{l}\text { Promoveu uma participação ativa na construção do conhecimento acerca de povos } \\
\text { tradicionais de sua região }\end{array}$ \\
\hline Ressaltou aspectos culturais do contexto em que os alunos estão inseridos \\
\hline Possibilitou o contato direto com indígenas em uma aldeia \\
\hline $\begin{array}{l}\text { Oportunizou o estabelecimento de relações entre os conhecimentos da disciplina de química } \\
\text { e as culturas indígenas }\end{array}$ \\
\hline Valorizou a autonomia dos alunos na construção do conhecimento \\
\hline Possibilitou aos alunos relacionarem conhecimentos filosóficos, históricos e literários \\
\hline $\begin{array}{l}\text { Promoveu reflexões críticas a respeito dos estereótipos e preconceitos em relação aos } \\
\text { indígenas }\end{array}$ \\
\hline
\end{tabular}

Fonte: Questionário aplicado pelos autores.

Todos os professores concordaram que o trabalho com a temática indígena envolvendo todas as disciplinas é mais efetivo do que de forma isolada. Dentre as contribuições apontadas, em relação à atuação do projeto integrador para potencializar o aprendizado, Cury, Souza e Moniz (2018) também verificaram, após a realização de sua intervenção, que uma das contribuições proporcionadas foi a promoção de reflexões críticas em relação ao preconceito sofrido pelos povos indígenas.

As contribuições apresentadas pelos docentes indicam como a vivência do PI foi importante para a formação dos alunos. Eles tiveram acesso ao conhecimento de forma integrada, puderam ter uma participação ativa na construção do conhecimento e as experiências vivenciadas tinham uma forte relação com o seu contexto. Este último ponto, aliás, talvez seja o mais significativo, uma vez que, apesar de o contato com indígenas ser corriqueiro no seu dia a dia, ainda havia muitos entendimentos distorcidos sobre esses povos, o que acarretava em visões preconceituosas e até mesmo desprezíveis.

\section{Percepções a respeito do projeto integrador sobre as corporalidades indígenas}

Nesse tópico dos alunos, a análise relaciona-se com a percepção deles a respeito das experiências vivenciadas no PI sobre as corporalidades indígenas. Para tanto, as questões tiveram por objetivo verificar a sua satisfação pela experiência (Quadro 8), os pontos positivos e negativos observados (Quadro 9) e se o trabalho em conjunto das disciplinas é melhor do que de forma isolada (Quadro 10). 
Quadro 8 - Satisfação em relação à vivência do projeto integrador

\begin{tabular}{|c|c|c|c|}
\hline \multicolumn{2}{|r|}{ Conjunto de respostas } & V.a. & $\%$ \\
\hline \multirow{3}{*}{ Sim } & Porque ampliou as possibilidades do conhecimento & 17 & 48,58 \\
\hline & $\begin{array}{l}\text { Por possibilitar o entendimento de que o conhecimento é constituído } \\
\text { pela interação de diferentes áreas }\end{array}$ & 11 & 31,43 \\
\hline & Pois diminuiu a quantidade de atividades das disciplinas & 4 & 11,43 \\
\hline \multirow[b]{2}{*}{ Não } & Em razão de algumas disciplinas terem dificuldade em abordar o tema & 2 & 5,71 \\
\hline & $\begin{array}{l}\text { Porque foi difícil compreender a temática sendo abordada por várias } \\
\text { disciplinas ao mesmo tempo }\end{array}$ & 1 & 2,85 \\
\hline
\end{tabular}

Fonte: Questionário aplicado pelos autores

A maior parte dos alunos demonstrou satisfação em relação à participação no PI. No que diz respeito aos motivos, a diminuição da quantidade de atividades das disciplinas também foi encontrado em trabalho realizado com projeto integrador por Braga et al. (2017), o que nos indica que as atividades avaliativas podem estar sendo aplicadas em excesso.

Em relação aos motivos que levaram alguns alunos a não ficarem satisfeitos com a vivência do PI, percebe-se que se referem a dificuldades de entendimento no processo de ensino e aprendizagem. É uma situação, de certa forma, esperada, posto que os professores participantes da proposta não possuíam experiência com esse tipo de trabalho. Sendo assim, faz-se necessário ajustes na realização de futuras propostas para que haja o seu aprimoramento, como podemos encontrar na literatura (SILVA; COSER, 2012).

Quadro 9 - Pontos positivos e negativos do projeto integrador

\begin{tabular}{|l|l|}
\hline \multicolumn{1}{|c|}{ Conjunto de respostas } \\
\hline \multirow{4}{*}{ Positivos } & Tema relevante \\
\cline { 2 - 3 } & A presença de aulas práticas \\
\cline { 2 - 3 } & A realização de aulas de campo \\
\cline { 2 - 3 } & A realização de atividades interdisciplinares \\
\cline { 2 - 3 } & A vivência de atividades em grupo \\
\cline { 2 - 3 } & A desconstrução de condutas preconceituosas \\
\cline { 2 - 3 } & Aulas mais atrativas \\
\cline { 2 - 3 } & A valorização das culturas indígenas \\
\hline \multirow{5}{*}{ Informações insuficientes sobre o tema em algumas disciplinas } \\
\cline { 2 - 3 } & Condições inadequadas para aulas práticas (ex.: calor excessivo) \\
\cline { 2 - 3 } & Pouco contato com os indígenas \\
\cline { 2 - 3 } & Alta quantidade de atividades nas disciplinas \\
\cline { 2 - 3 } & Permanência prolongada do mesmo assunto nas aulas \\
\cline { 2 - 3 } & Dificuldade em realizar trabalhos em grupo \\
\cline { 2 - 3 } & Tempo insuficiente para aprofundar alguns assuntos do tema \\
\cline { 2 - 3 } & A falta de comprometimento dos alunos \\
\hline
\end{tabular}

Fonte: Questionário aplicado pelos autores.

Os alunos apontaram vários pontos positivos e negativos acerca da experiência vivenciada. Em relação aos positivos, no trabalho desenvolvido por Cury, Souza e Moniz (2018) a realização de atividades interdisciplinares também foi destacada pelos alunos participantes. Já Paulon e Vieira (2017) e Oberderfer et al. (2016) relataram que os alunos ressaltaram que as aulas foram mais atrativas. 
Percepções similares às apresentadas pelos alunos também foram encontradas na literatura em relação aos aspectos negativos. Braga et al. (2017) verificaram que os participantes de sua intervenção apontaram para informações insuficientes sobre a temática em algumas disciplinas e também pouco tempo para o aprofundamento de alguns assuntos.

De um modo geral, podemos verificar que os pontos positivos destacados pelos alunos estão relacionados a mudanças metodológicas possibilitadas pelo PI e ao trabaIho com um tema de extrema importância. Por outro lado, nos negativos, a realização de ajustes na proposta, visando ao seu aprimoramento, deverá minimizar ou acabar com os principais pontos mencionados.

Quadro 10 - Abordagem do conteúdo nas disciplinas de forma isolada ou em conjunto

\begin{tabular}{|c|l|c|c|}
\hline \multicolumn{1}{|c|}{ Conjunto de respostas } & V.a. & $\%$ \\
\hline \multirow{5}{*}{ Conjunto } & Pois o conhecimento é compreendido de forma integrada & $\mathbf{1 2}$ & $\mathbf{3 4 , 2 8}$ \\
\cline { 2 - 4 } & Porque facilita o aprendizado & $\mathbf{6}$ & $\mathbf{1 7 , 1 4}$ \\
\cline { 2 - 4 } & Pelo fato de diminuir o volume de atividades das disciplinas & $\mathbf{6}$ & $\mathbf{1 7 , 1 4}$ \\
\cline { 2 - 4 } & Mas com as disciplinas mantendo a sua especificidade & $\mathbf{3}$ & $\mathbf{8 , 6 0}$ \\
\cline { 2 - 4 } & $\begin{array}{l}\text { Desde que as áreas de atuação de cada disciplina tenha mais } \\
\text { proximidade }\end{array}$ & $\mathbf{1}$ & $\mathbf{2 , 8 5}$ \\
\cline { 2 - 4 } & $\begin{array}{l}\text { Por tornar possível o aprofundamento do estudo sobre } \\
\text { determinado tema }\end{array}$ & $\mathbf{1}$ & $\mathbf{2 , 8 5}$ \\
\hline Isolada & Por ser mais fácil o aprendizado & $\mathbf{6}$ & $\mathbf{1 7 , 1 4}$ \\
\hline
\end{tabular}

Fonte: Questionário aplicado pelos autores.

Na última pergunta a maior parte dos alunos assinalou que prefere o desenvolvimento do conteúdo de forma integrada ao invés de isolada. A principal justificativa apresentada foi pelo fato de o conhecimento ser compreendido de modo integrado. Essa mesma percepção dos alunos também foi encontrada nos trabalhos desenvolvidos por Oberderfer et al. (2016), que apresentou uma experiência desenvolvida com um PI, e Silva, Greggio e Agne (2020), que verificaram a percepção de estudantes a respeito dos projetos integradores e das oficinas de integração.

Em relação aos alunos que ainda preferem o trabalho isolado pelas disciplinas, a justificativa é pelo fato de o aprendizado ser mais fácil. Isto pode estar relacionado com questões metodológicas e/ou domínio do tema por parte dos professores participantes. Caso esteja relacionado, o aperfeiçoamento de projetos posteriores poderá resultar na mudança desse entendimento.

\section{CONSIDERAÇÕES FINAIS}

Este artigo teve por finalidade apresentar a percepção de um grupo de professores e de alunos a respeito dos limites e possibilidades de um PI. As respostas indicam que o $\mathrm{PI}$ pode colaborar de maneira significativa no processo de ensino e aprendizagem, inclusive na temática proposta: as corporalidades indígenas. Há, contudo, situações que limitam o seu desenvolvimento e que devem ser consideradas no processo de planejamento. 
A principal contribuição proporcionada pelo $\mathrm{PI}$, apontada por professores e alunos é, indubitavelmente, a busca pela integração das áreas do conhecimento. Embora a forma como a realidade apresenta-se seja de modo totalitário, ao longo da história a produção do conhecimento foi sendo, progressivamente, fragmentada. Este fato culminou no surgimento das disciplinas primeiramente no ambiente científico e, posteriormente, no ambiente escolar. A compreensão da realidade, porém, fica prejudicada pelo acesso ao conhecimento de forma fragmentada. $\mathrm{O} \mathrm{PI}$, ao viabilizar a aproximação das áreas do conhecimento, por meio da atuação em conjunto das disciplinas, supera essa limitação e torna o processo de ensino e aprendizagem mais profícuo para professores e alunos.

A despeito do enaltecimento da integração dos conhecimentos, cabe ressaltar, também, o reconhecimento da valorização da diversidade cultural, sobretudo por se tratar de uma instituição de EPT. Comumente, acredita-se que em ambientes educativos desse sistema de ensino a predominância dos conhecimentos técnicos deveria sobressair-se em detrimento dos de natureza cultural. Como, no entanto, as respostas nos mostram, estes últimos são tão importantes quanto, até porque a presença deles é fundamental para alcançar a formação humana integrada preconizada nos documentos norteadores da EPT.

Como apontamentos a serem observados para uma experiência exitosa com $\mathrm{PI}$, ressaltamos a necessidade da confluência entre as políticas públicas e os papéis exercidos por gestores, professores e alunos. É fundamental que haja infraestrutura adequada, programas de formação continuada, a criação de tempos e espaços adequados no ambiente educacional e o comprometimento de professores e alunos. É a articulação desses diferentes fatores que possibilitará uma maior ou menor chance de sucesso com o PI.

Por fim, é importante frisar que as discussões e as tentativas de efetivação do currículo integrado nas instituições educacionais no país se acentuam cada vez mais, sobretudo na EPT. Experiências com projetos integradores, oficinas integradoras e projetos interdisciplinares são realizadas em diversos lugares na tentativa de superar a histórica fragmentação curricular. Para que isso, todavia, de fato, ocorra, deve haver a colaboração de todos os envolvidos com o ambiente escolar.

\section{REFERÊNCIAS}

AGNE, Sandra Aparecida Agne; DALBOSCO, Talita; JONCK, Gisela Gertrudes. Remédio de índio: contextualizando interdisciplinarmente os saberes populares e saberes escolares. In: SILVA, Adriano L. da; GREGGIO, Saionara; PASQUALLI, Roberta; AGNE, Sandra Aparecida Antonini (org.). O currículo integrado no cotidiano da sala de aula. 1. ed. Florianópolis: IFSC, 2016. p. 90-105. V. 1.

ARAÚJO, Ronaldo Marcos de Lima; FRIGOTTO, Gaudêncio. Práticas pedagógicas e ensino integrado. Revista Educação em Questão (On-line), v. 52, p. 61-80, 2015.

BRAGA, Adriano Honorato; MONTEIRO, Eneida Aparecida Machado; SANTOS, Mairon Marques; CUNHA, Flávia Bastos. Projeto integrador: análise de uma experiência do IF Goiano Campus Ceres. In: ARAÚJO, Adilson Cesar; SILVA, Cláudio Nei Nascimento da (org.). Ensino médio integrado no Brasil: fundamentos, práticas e desafios. 1. ed. Brasília: IFB, 2017. p. 216-226. V. 1.

BRANDÃO, Carlos Rodrigues. A pesquisa participante e a participação da pesquisa: um olhar entre tempos e espaços a partir da América Latina. In: BRANDÃO, Carlos Rodrigues; STRECK, Danilo (org.). Pesquisa participante: a partilha do saber. Aparecida: Idéias \& Letras, 2006.

BRANDÃO, Carlos Rodrigues; BORGES, Maristela Corrêa. A pesquisa participante: um momento da educação popular. Revista de Educação Popular, v. 6, p. 51-62, 2007. 
CARVALHO, Leonardo Emmanuel Fernandes. Articulando saberes: concepção docente sobre interdisciplinaridade e a prática dos projetos integradores dos cursos técnicos integrados do IFRN, Campus Pau dos Ferros. Dissertação (Mestrado em Educação) - Universidade do Estado do Rio Grande do Norte, Pau Programa de Pós-Graduação em Educação, dos Ferros, 2019.

CRIZEL, Lílian Escandiel; PASSOS, Camila Greff; DEL PINO, José Cláudio. O currículo integrado do proeja do IFRS - Campus Bento Gonçalves: uma possibilidade real e complexa de efetivação em sala de aula. Revista Contexto \& Educação, ljuí: Editora Unijuí, v. 28, p. 58-83, 2013.

CRUZ, Bruna Paula da; BORGES, João Felipe Barbosa; VIANA, Ana Paula Rocha; FREITAS NETO, Michele Maria; BARROS, Fabiana Castro Carvalho. O Projeto Integrador no Instituto Federal de Educação, Ciência e Tecnologia Fluminense - Campus Itaperuna, RJ: uma experiência em integração e interdisciplinaridade. In: Educação \& Tecnologia, v. 20, p. 45-58, 2015.

CURY, lára Leme Russo; SOUZA, José Gilberto; MONIZ, Maria Isabel D’Andrade. Interdisciplinaridade: uma prática para a compreensão da questão indígena. In: ENCONTRO REGIONAL DE ENSINO DE GEOGRAFIA: ENSINAR GEOGRAFIA COM A DIFERENÇA E COM A POLÍTICA, 6., 2018, Campinas. Anais [...]. Capinas, 2018.

FERNANDES, Natal Lânia Roque. Currículos e programas da EPCT. 1. ed. Fortaleza: UAB/IFCE, 2014. 118 p. V. 1.

GRÜMM, Cristiane Aparecida; CONTE, Hugo Donato Lazzari; LIDANI, Rangel. "Você conhece a sua história?": uma experiência para pensar o currículo integrado. In: SILVA, Adriano Larentes da; PASQUALLI, Roberta; GREGGIO, Saionara; AGNE, Sandra Aparecida Antonini (org.). O currículo integrado no cotidiano da sala de aula. 1. ed. Florianópolis: Editora do IFSC, 2016. p. 52-70. V. 1.

HENRIQUE, Ana Lúcia Sarmento; NASCIMENTO, José Mateus do. Sobre práticas integradoras: um estudo de ações pedagógicas na educação básica. Holos, Natal (on-line), v. 4, p. 63-76, 2015.

LIMA, Clara Paula de. A educação profissional e o currículo integrado no curso técnico em eletromecânica no IFRO - Campus Vilhena. 2017. Dissertação (Mestrado Profissional em Educação Escolar) - Universidade Federal de Rondônia, Programa de Pós-Graduação em Educação Escolar, Porto Velho, 2017.

LOPES, Alice Casimiro; MACEDO, Elizabeth Fernandes de. Teorias de currículo. 1. ed. São Paulo: Cortez, 2011. 279 p. V. 1.

MACHADO, Lucília Regina de Souza. Ensino Médio e técnico com currículos integrados: propostas de ação didática para uma relação não fantasiosa. In: MOLL, Jaqueline et al. (org.). Educação profissional e tecnológica no Brasil contemporâneo: desafios, tensões e possibilidades. 1. ed. Porto Alegre, RS: Artmed Editora, 2009.

MORAES, Francisco; KÜLLER, José Antônio. Currículos integrados no Ensino Médio e na educação profissional: desafios, experiências e propostas. São Paulo: Senac São Paulo, 2016.

MOREIRA, Antônio Flavio; CANDAU, Vera. Indagações sobre currículo: currículo, conhecimento e cultura. Brasília: SEB; MEC, 2008.

OBERDERFER, Lara Popov Zambiasi Bazzi; PASQUALLI, Roberta; BRESOLIN, Ademir; CALEGARO, Bruno Crestani. O currículo integrado e o ensino da informática: práticas interdisciplinares. O currículo integrado no cotidiano da sala de aula. In: SILVA, Adriano Larentes da; PASQUALLI, Roberta; GREGGIO, Saionara; AGNE, Sandra Aparecida Antonini (org.). O currículo integrado no cotidiano da sala de aula. 1. ed. Florianópolis: IFSC, 2016. p. 46-69. V. 1.

PAULON, Alessandra Ciambarella; VIEIRA, Daniel Pais Pires. Química e a história em suas relações no século XX: um caso de projeto interdisciplinar na sala de aula. In: ARAÚJO, Adilson Cesar Araújo; SILVA, Cláudio Nei Nascimento da (org.). Ensino Médio integrado no Brasil: fundamentos, práticas e desafios. 1. ed. Brasília: IFB, 2017. p. 216-226. V. 1.

RAMOS, Marise Nogueira. Possibilidades e desafios na organização do currículo integrado. In: RAMOS, Marise Ramos; FRIGOTTO, Gaudêncio; CIAVATTA, Maria (org.). Ensino Médio integrado: concepção e contradições. 1. ed. São Paulo: Cortez, 2005. p. 106-127. V. 1.

RAMOS, Marise Nogueira. Concepção do ensino médio integrado. Texto apresentado em seminário promovido pela Secretaria de Educação do Estado do Pará nos dias 8 e 9 de maio de 2008.

ROCHA, Alessandra da; SILVA, Maria Lúcia Ravela Nogueira da; FONSECA, Paola Barros de Faria. Projeto integrador do campus avançado São João da Barra. In: IV COLÓQUIO NACIONAL, 4., INTERNACIONAL A PRODUÇÃO DO CONHECIMENTO EM EDUCAÇÃO PROFISSIONAL: A REFORMA DO ENSINO MÉDIO (LEI 13.415/2017) E SUAS IMPLICAÇÕES PARA A EDUCAÇÃO PROFISSIONAL, 1., 2017. Natal. Anais [...]. Natal, RN, 2017. p. 1-12. V. 1.

SACRISTÁN, José Gimeno. O currículo: uma reflexão sobre a prática. Porto Alegre: Artmed, 2000. 
SAVIANI, Dermeval. Trabalho e educação: fundamentos ontológicos e históricos. Revista Brasileira de Educação, v. 12, p. 152-165, 2007.

SILVA, Fabio Machado da; GIOTTO, Joce Mary Mello. As oficinas de integração do curso técnico de nível médio integrado em informática do IFSC, Campus Chapecó: uma análise contextual. In: SILVA, Adriano Larentes da; PASQUALLI, Roberta; GREGGIO, Saionara; AGNE, Sandra Aparecida Antonini (org.). O currículo integrado no cotidiano de sala de aula. 1. ed. Florianópolis: Publicação do IFSC, 2016. p. 84-93. V. 1.

SILVA, Adriano Larentes da; COSER, Joni. A experiência do Projeto Integrador I no curso de Proeja em Eletromecânica do IF-SC Campus Chapecó. Revista Técnico-Científica, IFSC, v. 1, p. 9-19, 2012.

SILVA, Adriano Larentes da. Currículo Integrado. 1. ed. Florianópolis: Editora do IFSC, 2014. 97 p.

SILVA, Adriano Larentes da; GREGGIO, Saionara; AGNE, Sandra Aparecida Antonini. A integração curricular na percepção dos estudantes de três campus do Instituto Federal de Santa Catarina. Revista Brasileira de Educação Profissional e Tecnológica, v. 1, p. e7929, 2020.

SILVA-PEREIRA, Liz Carmem; SANTOS, José Ribamar Azevedo dos; OLIVEIRA NETO, Manoel Gonzaga de. Metodologias integradoras na educação profissional: construindo a ponte entre a base comum e as disciplinas técnicas no ensino técnico integrado. In: ARAÚJO, Adilson Cesar; SILVA, Cláudio Nei Nascimento da (org.). Ensino Médio integrado no Brasil: fundamentos, práticas e desafios. 1. ed. Brasília: Editora IFB, 2017. p. 150-165. V. 1. 